\title{
Laccase-Catalyzed Polymerization of Hydroquinone Incorporated with Chitosan oligosaccharide for Enzymatic Coloration of Cotton
}

Rubing Bai $^{a, b}$ Yuanyuan Yu ${ }^{a}$ Qiang Wang ${ }^{a, 1}$ Jinsong Shen $^{\text {b,2 }}$ Jiugang Yuan $^{a} \quad$ Xuerong Fan $^{a}$

${ }^{a}$ Key Laboratory of Science and Technology of Eco-Textile, Ministry of Education , Jiangnan University, Wuxi, Jiangsu 214122, China

${ }^{\mathrm{b}}$ Textile Engineering and Materials Research Group, School of Design, De Montfort University, The Gateway, Leicester LE1 9BH, UK

\begin{abstract}
Chitosan oligosaccharide (COS), a water-soluble carbohydrate obtained from chemical or enzymatic hydrolysis of chitosan, has similar structure and properties to non-toxic, biocompatible and biodegradable chitosan. However, COS has many advantages over chitosan due to its low molecular weight and high water solubility. In the current work, COS was incorporated in the laccase-catalyzed polymerization of hydroquinone. The laccase-catalyzed polymerization of hydroquinone with or without COS was investigated by using simple structure of glucosamine hydrochloride as an alternative to $\mathrm{COS}$ to understand the mechanism of COS-incorporated polymerization of hydroquinone. Although polyhydroquinone can be regarded as the polymeric colorant with dark brown color, there is no affinity or chemical bonding between
\end{abstract}

\footnotetext{
${ }^{1}$ Prof. Qiang Wang (qiang_wang@163.com). Key Laboratory of Science and Technology of Eco-Textile, Ministry of Education, Jiangnan University, Wuxi, Jiangsu 214122, China.

2 Prof. Jinsong Shen (jshen@dmu.ac.uk). Textile Engineering and Materials Research Group, School of Design, De Montfort University, The Gateway, Leicester LE1 9BH, UK
} 
polyhydroquinone and cotton fibers. Cotton fabrics were successfully in-situ dyed into brown color through the laccase-catalyzed polymerization of hydroquinone by incorporating with COS as a template. The presence of COS enhanced the dye uptake of polyhydroquinone on cotton fibers due to high affinity of $\operatorname{COS}$ to cotton and covalent bonding between COS and polyhydroquinone during laccase catalysis. This novel approach not only provides a simple route for the biological coloration of cotton fabrics, but also presents a significant way to prepare functional textiles with antibacterial property.

Key words: Chitosan oligosaccharide (COS); phenol; laccase; polymerization; cotton fabric

\section{Introduction}

Chitosan is a biopolymer obtained from N-deacetylation of chitin. It consists of $\beta-(1-4)-2-$ amino-D-glucose and $\beta$-(1-4)-2-acetamido-D-glucose units [1]. As one of the most popular natural carbohydrates, chitosan has been widely used because of its immunostimulatory activities, biocompatibility, film-forming ability, anticoagulant and other structural properties [2-4]. However, higher molecular weight of chitosan limits its applications in medicine and food industries. For example, chitosan cannot be used as an antibacterial agent when its molecular weight is greater than $30 \mathrm{kDa}$, due to the poor solubility in aqueous solutions at neutral $\mathrm{pH}$ [5].

Chitosan oligosaccharide (COS) is depolymerized from chitosan by acidic and enzymatic hydrolysis processes $[6,7]$. It has the same structure units as chitosan except lower molecular weight, resulting in better solubility in aqueous solutions $[8,9]$. Recently, there is an increasing interest in its antioxidative and antimicrobial activities. COS with medium molecular weights 
exhibited the highest radical scavenging activity against all tested radicals including 1, 1diphenyl-2-picrylhydrazyl (DPPH) radicals, hydroxyl radicals, superoxide radicals and carboncentered radicals. Furthermore, the scavenging activity of COS was dependent on their degree of deacetylation and molecular weights [10]. Eom et al. synthesized novel antioxidant polymers through conjugating COS with natural phenolic acids which can be used as potential agents for pharmaceutical industry [11]. Tikhonov et al. indicated that COS showed high activities against all experimental bacteria, yeast and filamentous fungus [12]. In addition, more attentions have been paid to its abundant biological activities such as anti-inflammatory, anti-tumor, anticancer, and anti-fungal [13-15].

Enzyme-catalyzed oxidative polymerization of phenols has been investigated extensively as a novel alternative route for conventional polymerization due to its advantages of milder synthesis conditions, less energy consumption and low toxicity [16-20]. In the last two decades, template-oriented polymerization of phenol in buffer was reported many times by Kim et al. Varied templates including poly(ethylene glycol) (PEG), poly(ethylene glycol) monododecyl ether (PEGMDE), and poly(ethylene glycol)-poly(propylene glycol)-poly(ethylene glycol) (PEG-PPG-PEG) were used in these investigations [21-23]. The presence of these templates greatly improved the phenylene unit content of polyphenol [22]. PEG was also used as a template for laccase-mediated synthesis of poly(caffeic acid) in a previous study [24]. In the present work, hydroquinone (HQ) was enzymatically polymerized by laccase using COS as an "active template". Different to the above-mentioned templates, COS can be covalently bonded to phenolic monomers during the laccase-catalyzed polymerization of phenols, resulting in more stable bonds between COS as template and polyphenols. On the other hand, COS possesses 
excellent antibacterial activity and high affinity to cellulose fibers, providing functionality to textiles. Structure of the polyhydroquinone (PHQ)/COS complex was investigated by FTIR, UPLC-TQD-ESI-MS, and ${ }^{1} \mathrm{H}-\mathrm{NMR}$ analysis. The proposed mechanism and interactions between hydroquinone and COS were schematically depicted in Fig. 1. Hydroquinone was oxidized and further polymerized to polyphenol using laccase. During the enzymatic polymerization, PHQ was also covalently bonded with COS via Schiff-base and Michael-addition reactions. The synthesized PHQ/COS complex was successfully applied for functionalization of cotton fabrics.

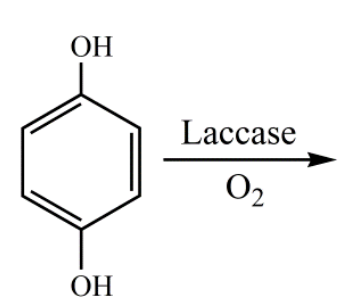

Hydroquinone

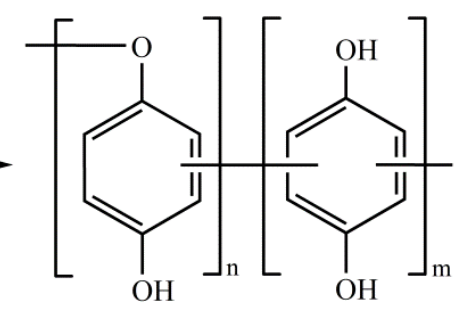

Polyhydroquinone
Chitosan oligosaccharide (COS)

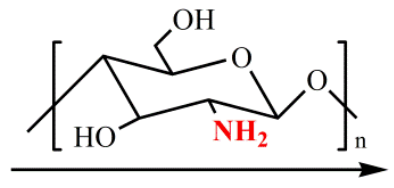

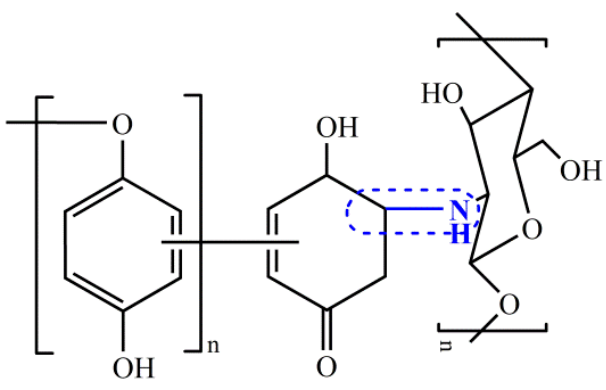

Michael type

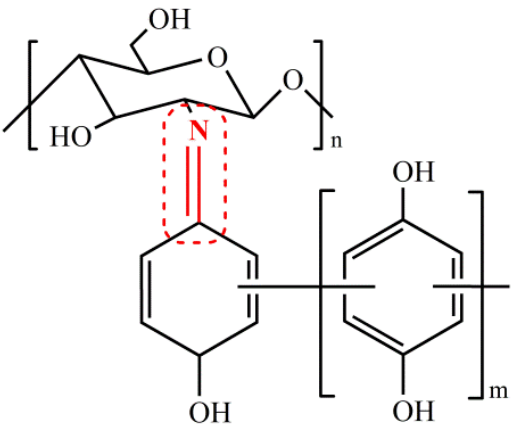

Schiff base

Fig.1 Schematic illustration of chitosan oligosaccharide (COS) templated polymerization of hydroquinone by laccase

\section{Materials and Methods}

\section{Materials and Chemicals}

Laccase (EC 1.10.3.2) from Trametes versicolor, 2, 2'-azino-bis-(3-ethylthiazoline-6- 
sulfonate) (ABTS, $\left.\varepsilon_{420}=36,000 \mathrm{M}^{-1} \times \mathrm{cm}^{-1}\right)$ and hydroquinone $\left(\mathrm{HQ}, \mathrm{C}_{6} \mathrm{H}_{6} \mathrm{O}_{2}\right)$ were supplied by Sigma-Aldrich and used without further purification. Chitosan oligosaccharide, (COS, $\left(\mathrm{C}_{6} \mathrm{H}_{11} \mathrm{NO}_{4}\right)_{\mathrm{n}}$, molecular weight $\leq 2,000 \mathrm{Da}, 90 \%$ deacetylated) were purchased from Baomanbio Co., Ltd. (Shanghai, China). Glucosamine hydrochloride (GAH) was provided by Aladdin Reagent Co., Ltd. (Shanghai, China). All other chemicals used were analytical grade and supplied by Sinopharm Chemical Reagent Co., Ltd. (Shanghai, China).

\section{Assay of Laccase}

The activity of laccase was measured by incubating $0.1 \mathrm{~mL}$ of $2 \mathrm{~g} / \mathrm{L}$ laccase with $2.9 \mathrm{~mL}$ of $0.5 \mathrm{mM}$ ABTS in $50 \mathrm{mM}$ acetate buffer at $\mathrm{pH}$ 5. The absorbance due to enzymatic oxidation of ABTS was monitored at $420 \mathrm{~nm}$ using a spectrophotometric UV-1800(Shimadzu). Time were recorded every 0.05 absorbance increment. One unit of laccase (U) is defined as the amount of laccase required to oxidize $1 \mu \mathrm{mol}$ of ABTS in one minute.

\section{Enzymatic Oxidation and Polymerization of Phenols}

HQ $(0.11 \mathrm{~g}, 1 \mathrm{mmol})$ and $\operatorname{COS}(0.2 \mathrm{~g})$ were dissolved in $50 \mathrm{~mL}$ of $0.2 \mathrm{M}$ acetate buffer at $\mathrm{pH}$ 5 in the absence or presence of laccase with enzyme activity of $0.1 \mathrm{U} / \mathrm{mL}(0.6 \mathrm{U} / \mathrm{mg})$. The mixture was agitated at a speed of $30 \mathrm{rpm}$ (revolution per minute) in a shaker water bath set at $50^{\circ} \mathrm{C}$ for $5 \mathrm{~h}$. After that, the polymeric materials were precipitated through evaporation and then repeatedly washed with methanol, and subsequently lyophilized at $-50^{\circ} \mathrm{C}$. The same reaction without $\mathrm{COS}$ was also conducted for comparison.

Glucosamine is a prominent part of the structure of the polysaccharides like chitosan. Considering the simpler structure of glucosamine hydrochloride (GAH), GAH was used as model unit compound of COS to investigate the mechanism of polymerization by laccase. Briefly, $2 \mathrm{~g} / \mathrm{L}$ 
GAH was mixed with $0.5 \mathrm{~g} / \mathrm{L} \mathrm{HQ}$ in a test tube, and $0.1 \mathrm{U} / \mathrm{mL}$ laccase was added subsequently. The test tube was then rotated at a speed of $30 \mathrm{rpm}$ in a shaker water bath set at $50^{\circ} \mathrm{C}$ for 2 hour for enzymatic polymerization of HQ.

\section{Preparation of Bio-functionalized Cotton Fabrics}

Cotton fabric samples were treated by following the same procedure. Swatch of cotton fabric ( $1 \mathrm{~g}$, about $5 \mathrm{~cm}^{2}$ ) was immersed in $0.2 \mathrm{M}$ acetate buffer ( $\mathrm{pH}$ 5) containing HQ (30 mg, $3 \%$ o.w.f) and $\operatorname{COS}(0.12 \mathrm{~g})$ with $0.1 \mathrm{U} / \mathrm{mL}$ of laccase at a liquor-to-goods ratio of 50:1 and treated at 50 ${ }^{\circ} \mathrm{C}$ for $5 \mathrm{~h}$ at a rotation speed of $30 \mathrm{rpm}$. After the enzymatic treatment, the cotton samples were washed thoroughly with deionized water and left to air-dry.

\section{Characterization of PHQ and PHQ/COS Complex}

\section{UV-Vis Spectrum Analysis}

The synthesis procedure of PHQ/COS complex catalyzed by laccase was monitored using a UV-1800 UV/Visible Spectrophotometer (Shimadzu, Japan) at a wavelength range of 225-325 $\mathrm{nm}$.

\section{FTIR Spectroscopy}

The spectra of PHQ and PHQ/COS complex were obtained using a Nicolet iS10 FT-IR spectrometer (Thermo Fisher Scientific, USA). Prior to data collection, background signal was scanned using potassium bromide $(\mathrm{KBr})$ powder. The lyophilized polymer products and matrix $\mathrm{KBr}$ were mixed at weight ratios of 1:200. At least 32 scans were carried out in order to achieve adequate signal-to-noise ratio. The spectra were collected at room temperature from 500 to 4000 $\mathrm{cm}^{-1}$, with a resolution of $8 \mathrm{~cm}^{-1}$. 


\section{Nuclear Magnetic Resonance (NMR) Measurements}

PHQ and PHQ/COS complex were isolated from the reaction solution via centrifugation dried overnight under vacuum as described above. The proton nuclear magnetic resonance $\left({ }^{1} \mathrm{H}-\right.$ NMR) spectra of extracted PHQ and PHQ/COS complex dissolved in deuterated dimethylsulfoxide (DMSO) were recorded by using tetramethylsilane (TMS) as an internal standard on a Bruker Avance III spectrometer (Bruker, Germany) at an operating frequency of $400 \mathrm{MHz}$.

\section{Ultra-Performance Liquid Chromatography-Triple Quadrupole Detection-Electro Spray Ionization Tandem Mass Spectrometry (UPLC-TQD-ESI-MS)}

UPLC separation of laccase-catalyzed oxidative reaction solution of PHQ and PHQ/COS complex was carried out using a Waters/Acquity UPLC (Waters, Milford, MA, USA) set at a flow rate of $0.3 \mathrm{~mL} / \mathrm{min}$ through gradient elution. $0.1 \%$ (v/v) formic acid water solution and $0.1 \%$ $(\mathrm{v} / \mathrm{v})$ formic acid acetonitrile solution were selected as mobile phases A and B respectively to perform on the column, $\mathrm{BEH} \mathrm{C18,}(1.7 \mu \mathrm{m}$ particle size; $2.1 \mathrm{~mm}$ internal diameter $\times 50 \mathrm{~mm}$ length) at the column temperature of $45{ }^{\circ} \mathrm{C}$. The column was flushed with the mixture of $5 \%$ eluent $\mathrm{A}$ for $1 \mathrm{~min}$, changed to $60 \%$ phase $\mathrm{A}$ for $3 \mathrm{~min}$, followed by $1 \%$ phase $\mathrm{A}$ for $3 \mathrm{~min}$, and finally changed back to $5 \%$ phase A for 1 min to complete (detection wavelength $280 \mathrm{~nm}$ ) [25]. The optimized electrospray parameters were as follows: Capillary voltage $3.5 \mathrm{kV}$, cone voltage $30 \mathrm{kV}$, ion energy $0.5 \mathrm{eV}$ and cone gas flow of $50 \mathrm{~L} / \mathrm{h}$, respectively [26].

\section{Thermogravimetric Analysis (TGA)}

The PHQ and PHQ/COS complex were tested for TGA using a TGA/SDTA 851e thermogravimetric analyzer (Mettler Toledo, Switzerland), in which approximately $5 \mathrm{mg}$ of each 
sample was used. The samples were heated from $50{ }^{\circ} \mathrm{C}$ to $600{ }^{\circ} \mathrm{C}$ at a heating rate of $10{ }^{\circ} \mathrm{C} / \mathrm{min}$ under nitrogen atmosphere.

\section{Properties of Modified Cotton Fabrics}

\section{Color Measurement}

During the laccase-catalyzed functionalization process, cotton fabrics were also colored into light brown. After the enzymatic process, cotton samples were thoroughly washed several times with deionized water, and then dried overnight at room temperature.

The colorimetric properties of the treated cotton fabrics were analyzed at $400 \mathrm{~nm}$ using a Color-Eye 7000 A Spectrophotometer (Gretag Macbeth, USA), in terms of CIELab values (L*, $\mathrm{a}^{*}$ and $\mathrm{b}^{*}$ ), with the standard illuminant D65 and a $10^{\circ}$ observer. The color depth (K/S value) of cotton fabrics was calculated based on Kubelka-Munk equation, as shown in Equation (1).

$\mathrm{K} / \mathrm{S}=(1-\mathrm{R})^{2} / 2 \mathrm{R}$

Where $\mathrm{K}$ is the absorbance coefficient, $\mathrm{S}$ is the scattering coefficient, and $\mathrm{R}$ is the reflectance ratio.

The K/S values of the treated cotton fabrics before and after standard washing were measured to assess durability of color to wash. Washing of the treated cotton fabrics (dimension: $5 \mathrm{~cm} \times 5 \mathrm{~cm}$ ) was carried out according to ISO 105-C06-B1S:2010 standard. After 5, 10, and 25 washing cycles, the treated cotton fabrics were rinsed with deionized water and dried at room temperature for measurement [27].

\section{Antibacterial testing}

The antibacterial activity of the modified cotton fabrics against the growth of Escherichia coli (E. coli) was examined according to the standard GB/T 20944.3-2008. Cotton samples of 
$0.50 \mathrm{~g}$ were cut into pieces and added to flasks containing $50 \mathrm{~mL}$ phosphate buffer solution. The concentration of the prepared inoculum of $E$. coli was approximately $2.5 \times 10^{5} \mathrm{CFU} / \mathrm{mL}$. The inoculum of $5 \mathrm{~mL}$ was added into each flask and incubated at $37{ }^{\circ} \mathrm{C}$ for $18 \mathrm{~h}$. Finally, $1 \mathrm{~mL}$ of the suspension containing bacteria was taken from each flask, and serial 10-fold dilutions were subsequently performed for quantitative measurement. After incubation at $37{ }^{\circ} \mathrm{C}$ for $24 \mathrm{~h}$, the numbers of colony forming units on the dishes of Enumeration agar (EA) were recorded. The antimicrobial percentage of the cotton samples was calculated according to Equation (2).

Antimicrobial percentage $(\%)=\left(1-\mathrm{C} / \mathrm{C}_{0}\right) \times 100$

Where $\mathrm{C}_{0}$ is the CFUs of control group and $\mathrm{C}$ is the CFUs of cotton samples.

The durability tests of antimicrobial activity were the same as described above.

\section{Results and Discussion}

\section{Uv-vis Spectrophotometry Analysis of PHQ and PHQ/COS Complex}

Hydroquinone (HQ) was enzymatically oxidized by laccase to produce free radicals and further polymerized in the absence or presence of COS. In order to understand possible reaction pathway of COS-enhanced polymerization of HQ via laccase catalysis, the UV-Vis spectra of HQ/COS reaction solution at various periods of the time were recorded, as shown in Fig. 2. For the laccase-catalyzed reaction with HQ in the absence of COS, the maximum absorption peak at around $289 \mathrm{~nm}$ decreased with increasing reaction time, while a new peak at around $245 \mathrm{~nm}$ appeared. The band at around $289 \mathrm{~nm}$ is one of the characteristic absorption bands of phenyl groups [28]. With the addition of COS to the system of laccase catalyzed oxidation of HQ, the absorption peak shifted from $289 \mathrm{~nm}$ of HQ to $284 \mathrm{~nm}$ of HQ/COS complex after 1 hour reaction. Moreover, the shifted peak at $284 \mathrm{~nm}$ showed gradual increase rather than decease with 
increasing time. The changes in the UV spectra during laccase catalysis of HQ were most probably caused by the formation of $p$-quinone structures and homo-molecular coupled PHQ with different molecular weights [29]. Simultaneously, Schiff base reactions occurred between p-quinone structure of PHQ and amino groups of COS, as shown in Fig. 2b, resulting in the decrease in the concentration of $p$-quinones. Thus, the band at $289 \mathrm{~nm}$ shifted to $284 \mathrm{~nm}$ and the absorption peak at around $284 \mathrm{~nm}$ increased as the time lapsed. This could confirm the reactions between COS and hydroquinone.
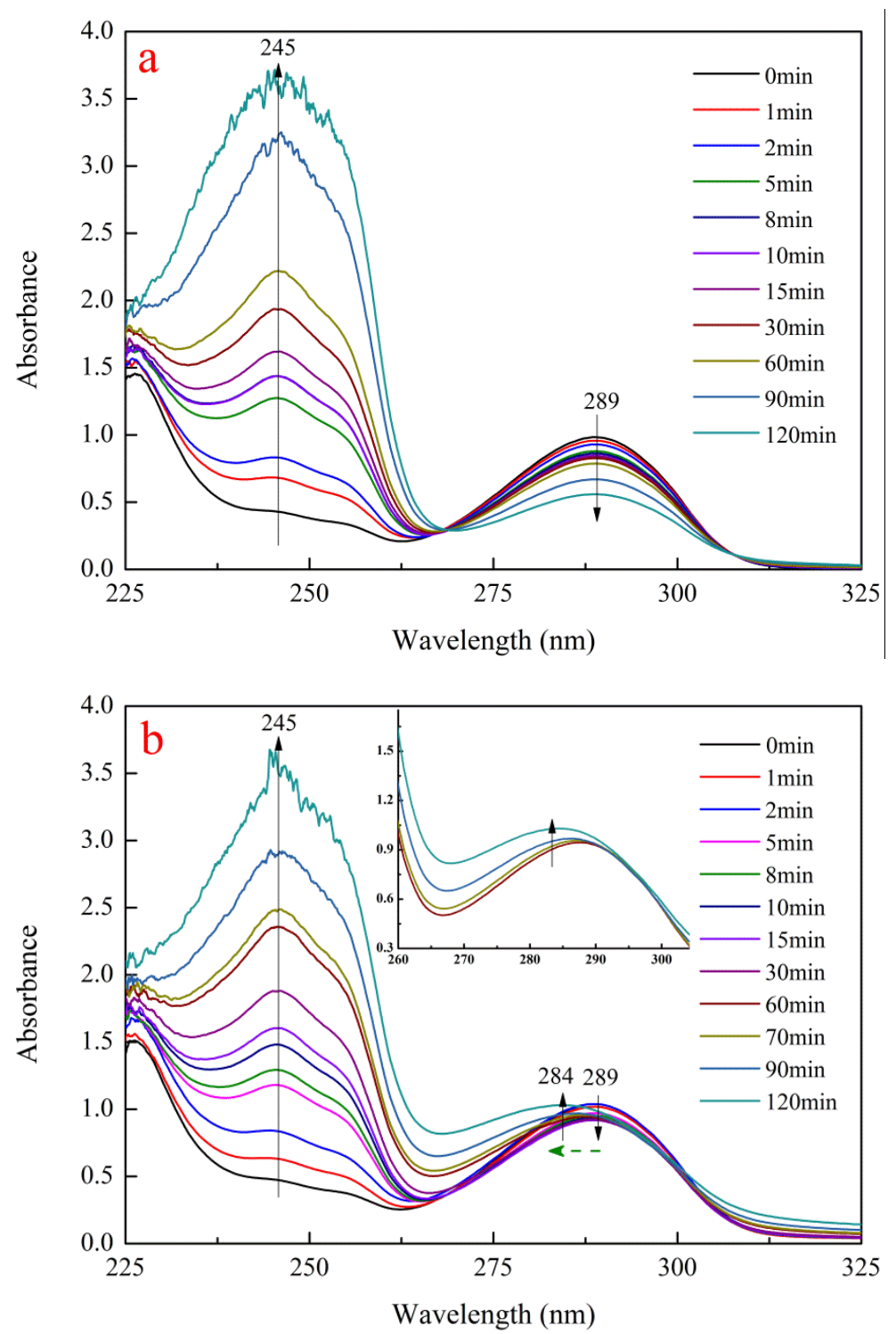

Fig. 2 UV-Vis spectra of complex reaction solution at various periods: (a) HQ and laccase; (b and insert) $\mathrm{HQ}$, laccase and COS. 


\section{Characterization of the structure of the PHQ/COS complex}

\section{FT-IR Analysis of PHQ and PHQ/COS complex}

Molecular structures of the PHQ, PHQ/COS complex and COS were characterized by FTIR spectra (Fig. 3).

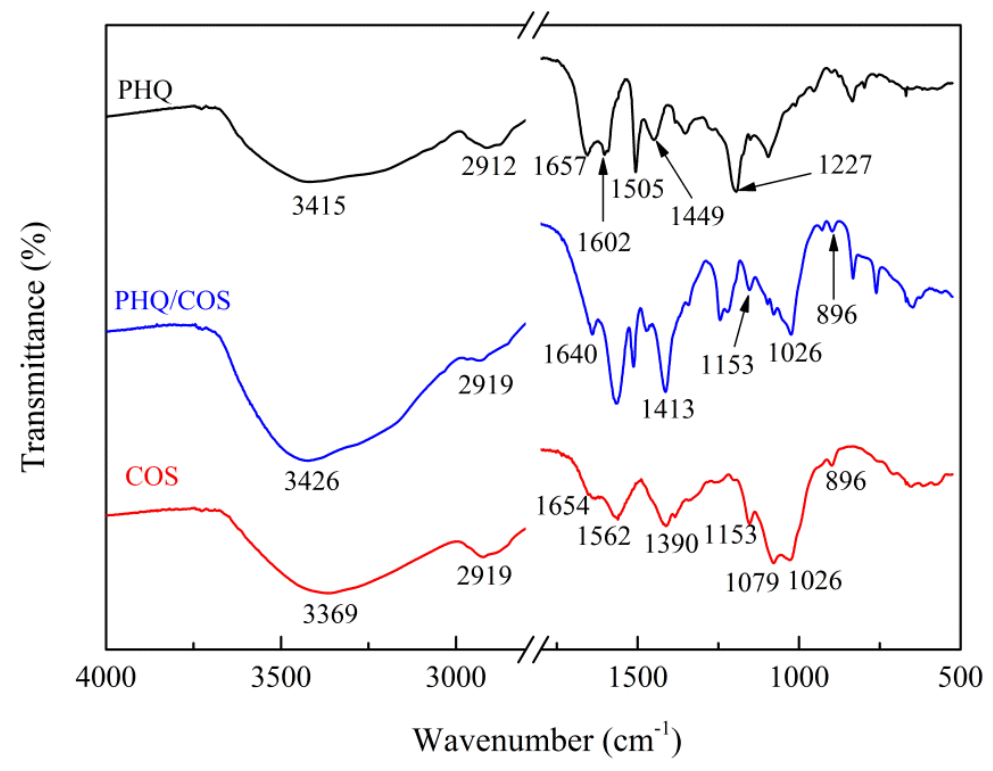

Fig.3 FT-IR spectra of PHQ, PHQ/COS complex and COS

For the spectrum of PHQ, the broad peak at $3415 \mathrm{~cm}^{-1}$ represented phenolic O-H vibration band. Peaks between 1449 and $1602 \mathrm{~cm}^{-1}$ belonged to the aromatic skeletal vibration. Moreover, the peak at $1657 \mathrm{~cm}^{-1}$ was attributed to quinone $\mathrm{C}=\mathrm{O}$ vibration band, and another peak at 1227 $\mathrm{cm}^{-1}$ corresponded to phenolic C-O vibration band [30].

In the case of PHQ/COS complex spectrum, the strong and broad absorption band at around $3429 \mathrm{~cm}^{-1}$ was caused by stretching vibration of $-\mathrm{OH}$ groups of PHQ molecules and inter- and intra-molecular H-bonds of COS molecules [31]. Some characteristic absorption peaks of PHQ and COS were also detected. For example, the peaks between 1413 and $1602 \mathrm{~cm}^{-1}$ were due to aromatic skeletal vibration of PHQ. As for COS, the band at around $2919 \mathrm{~cm}^{-1}$ was attributed to the $\mathrm{C}-\mathrm{H}$ stretch of $\mathrm{CH}_{2}$ groups. The peaks at 1153,1026 and $896 \mathrm{~cm}^{-1}$ were caused by anti- 
symmetric stretching vibration of C-O-C bridge, skeletal vibration involving the $\mathrm{C}-\mathrm{O}$ stretch of primary and second hydroxyl and asymmetric stretching of $\beta$-D-glycosidic, respectively [32-35]. Meanwhile, there are also changes at the shoulder of the $1640 \mathrm{~cm}^{-1}$ band, which could be attributed to the $\mathrm{C}=\mathrm{N}$ stretching mode of imines, further confirming the occurrence of Schiffbase reactions between COS and PHQ [36].

\section{${ }^{1}$ H-NMR analysis}

HQ, COS and the extracted polymers (PHQ and PHQ/COS complex) under the catalysis of laccase were dissolved in deuterated DMSO-d6 for ${ }^{1} \mathrm{H}-\mathrm{NMR}$ analysis. The obtained spectra are shown in Fig. 4.

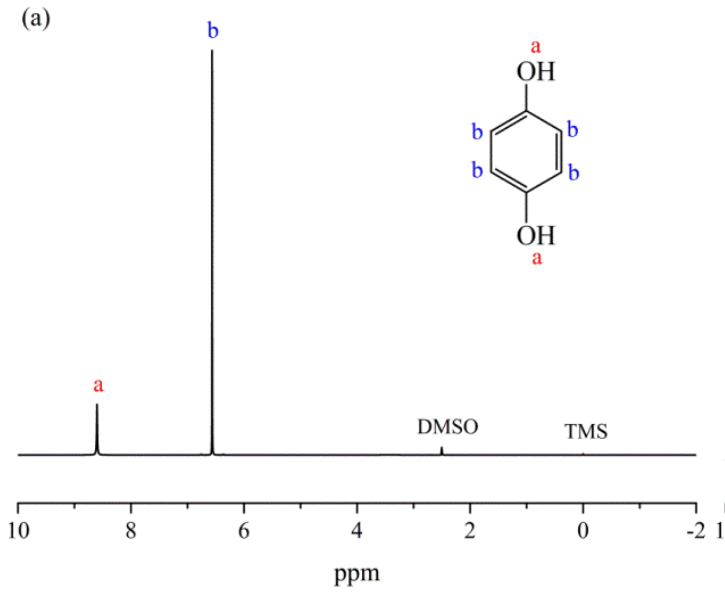

(b)

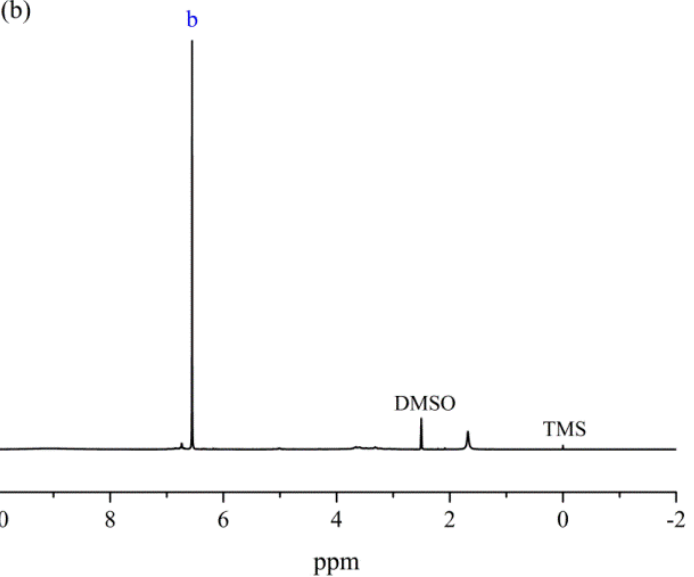

(c)

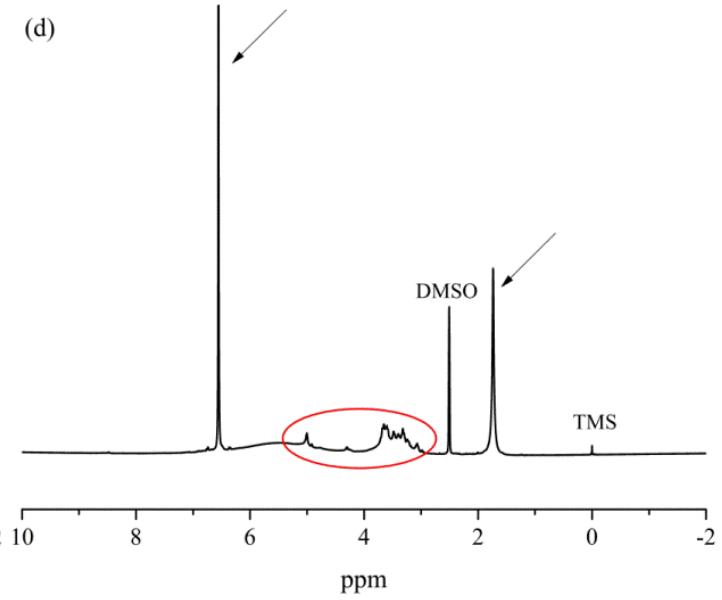

Fig. $4{ }^{1} \mathrm{H}-\mathrm{NMR}$ spectra of HQ (a), PHQ (b), COS (c) and PHQ/COS complex (d)

For the spectrum of HQ exhibited in Fig. 4a, the peak at about 8.60 ppm (peak a) was 
attributed to characteristic phenolic hydroxyl groups. Another sharp peak at $6.56 \mathrm{ppm}$ (peak b) was attributed to protons of aromatic ring, according to the report on the proton $(1 \mathrm{H})$ resonances [37]. Fig. 4b shows the characteristics of the synthesized PHQ by laccase. The decrease in the amount of hydroxyl protons during the laccase-catalyzed polymerization of HQ may be the cause for the disappearance of peak at $8.60 \mathrm{ppm}$. For the COS, the peak at $1.885 \mathrm{ppm}$ in Fig. 4c was attributed to the hydrogen proton of amino groups, while multiple peaks from 3.05 to $5.5 \mathrm{ppm}$ belonged to the hydroxyl protons and methyl protons of COS. As for the synthesized PHQ/COS complex (Fig. 4d), the multiple peaks from 2.99 to $5.2 \mathrm{ppm}$ could be attributed to hydroxyl protons and methylene protons resonance of COS (see the area with red circle). Moreover, two new peaks detected at 1.73 and $6.55 \mathrm{ppm}$ were corresponding to the hydrogen proton resonance of PHQ with COS. These NMR results could further demonstrate that PHQ really reacted with COS.

\section{UPLC-TOD-ESI-MS analysis of PHQ/GAH complex}

Chitosan is a polysaccharide, comprising units of glucosamine and $\mathrm{N}$-acetyl-glucosamine. Glucosamine hydrochloride (GAH) was used as the model compound of COS to investigate the mechanism of laccase-catalyzed polymerization. UPLC-TOD-ESI-MS profiles obtained at 280 $\mathrm{nm}$ from $\mathrm{PHQ} / \mathrm{GAH}$ complex reaction solutions were analyzed. As shown in Fig. 5, the reaction mixture was separated into five major peaks by UPLC because of different polarities of the products. Different retention time of main polymerized products are shown at $0.60,0.96,1.44$, 4.49, and 7.04 min (peak a - e), respectively. 


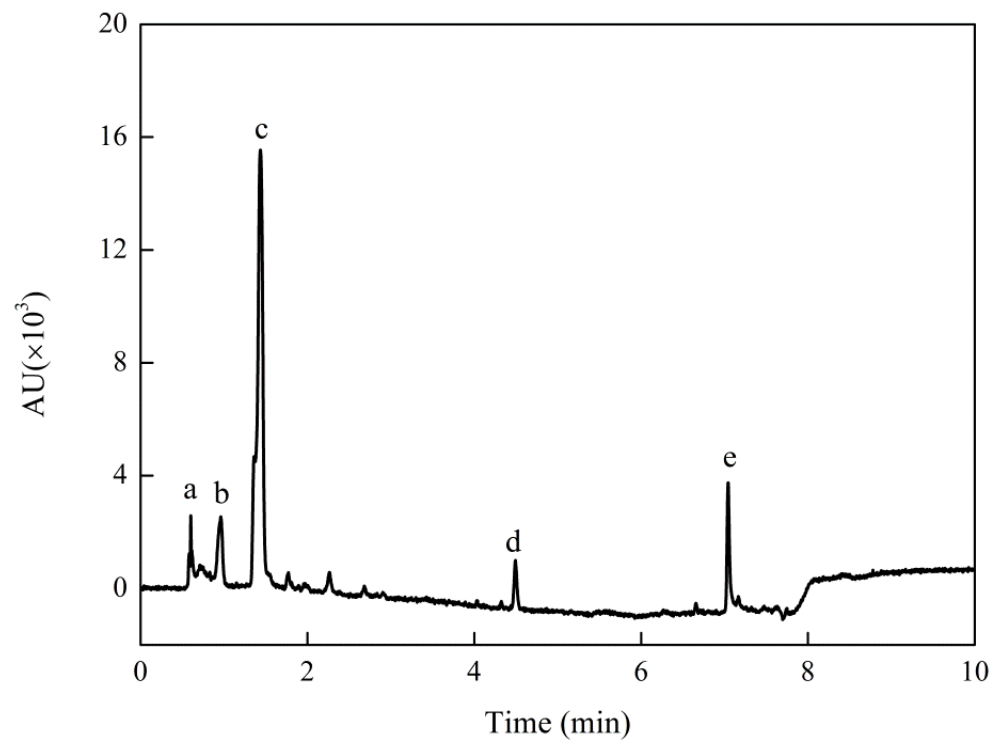

Fig. 5 UPLC-TOD UV spectrum (absorbance at $280 \mathrm{~nm}$ ) of PHQ/GAH solution

The information of MS fragments under each UPLC peak observed during ESI-MS analysis was shown in Fig. 6. Comparing all the MS data, m/z ratios at 126, 321 and 327 belonged to HQ trimers $\left(\mathrm{M}_{3}+\mathrm{NH}_{4}{ }^{+}, \mathrm{M}_{3}+\mathrm{H}^{+}\right)$, respectively; $\mathrm{m} / \mathrm{z}$ ratios at 180, 202 and 359 were attributed to $\mathrm{GAH}$ $\left(\mathrm{N}+\mathrm{H}^{+}\right),\left(\mathrm{N}+\mathrm{Na}^{+}\right)$and adduct of $\mathrm{GAH}\left(2 \mathrm{~N}+\mathrm{H}^{+}\right)$, respectively. It could be inferred that $\mathrm{HQ}$ trimers were possibly formed via linkages of phenyl-phenyl (ph-ph) or oxygen-phenyl (O-ph) [38]. According to the mechanism of Schiff-base and Michael addition reactions, it was deduced that $\mathrm{m} / \mathrm{z}$ ratios at 287,292 and 415 were probably the products from the reactions between HQ derivatives and GAH under the laccase catalysis. All the possible structural formulas of HQ trimers and PHQ/GAH complex were listed in Fig.7. The results were consistent with the FTIR and ${ }^{1} \mathrm{H}-\mathrm{NMR}$ results of $\mathrm{PHQ} / \mathrm{COS}$ complex. 

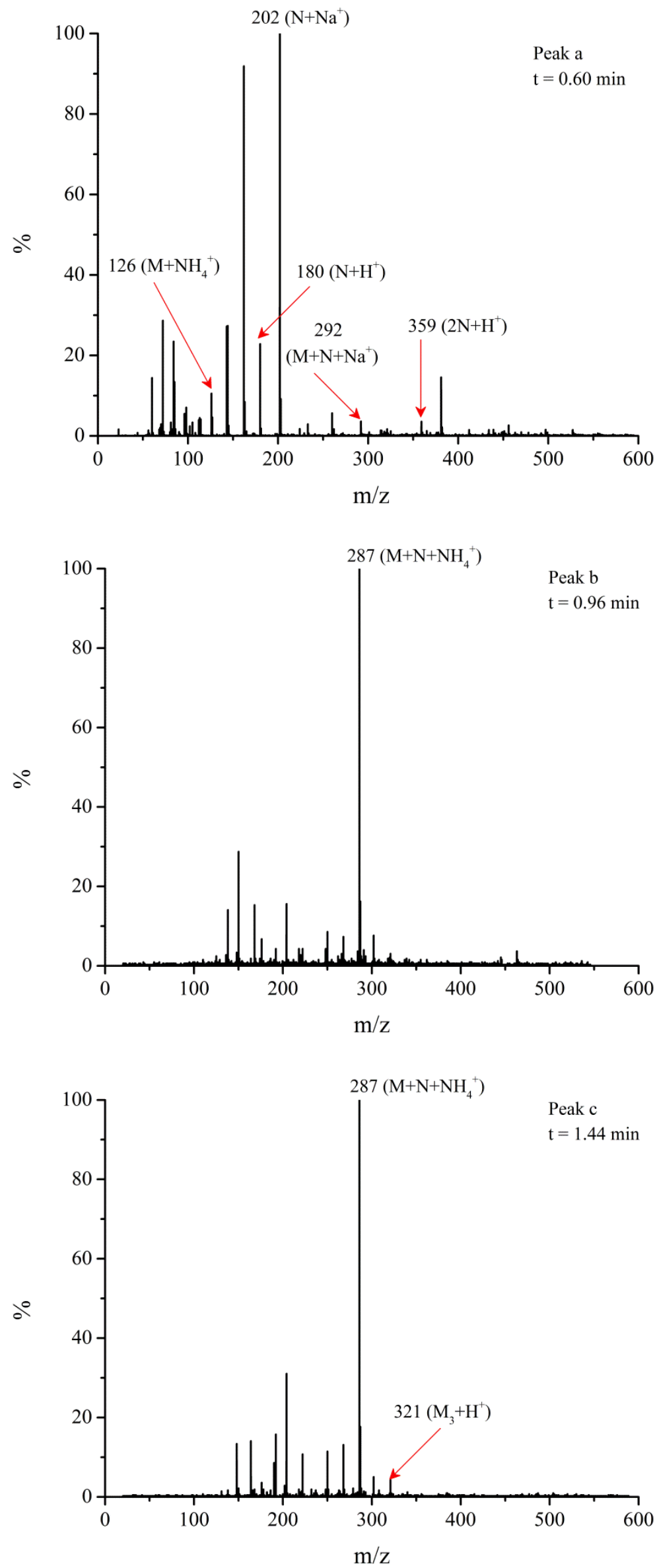

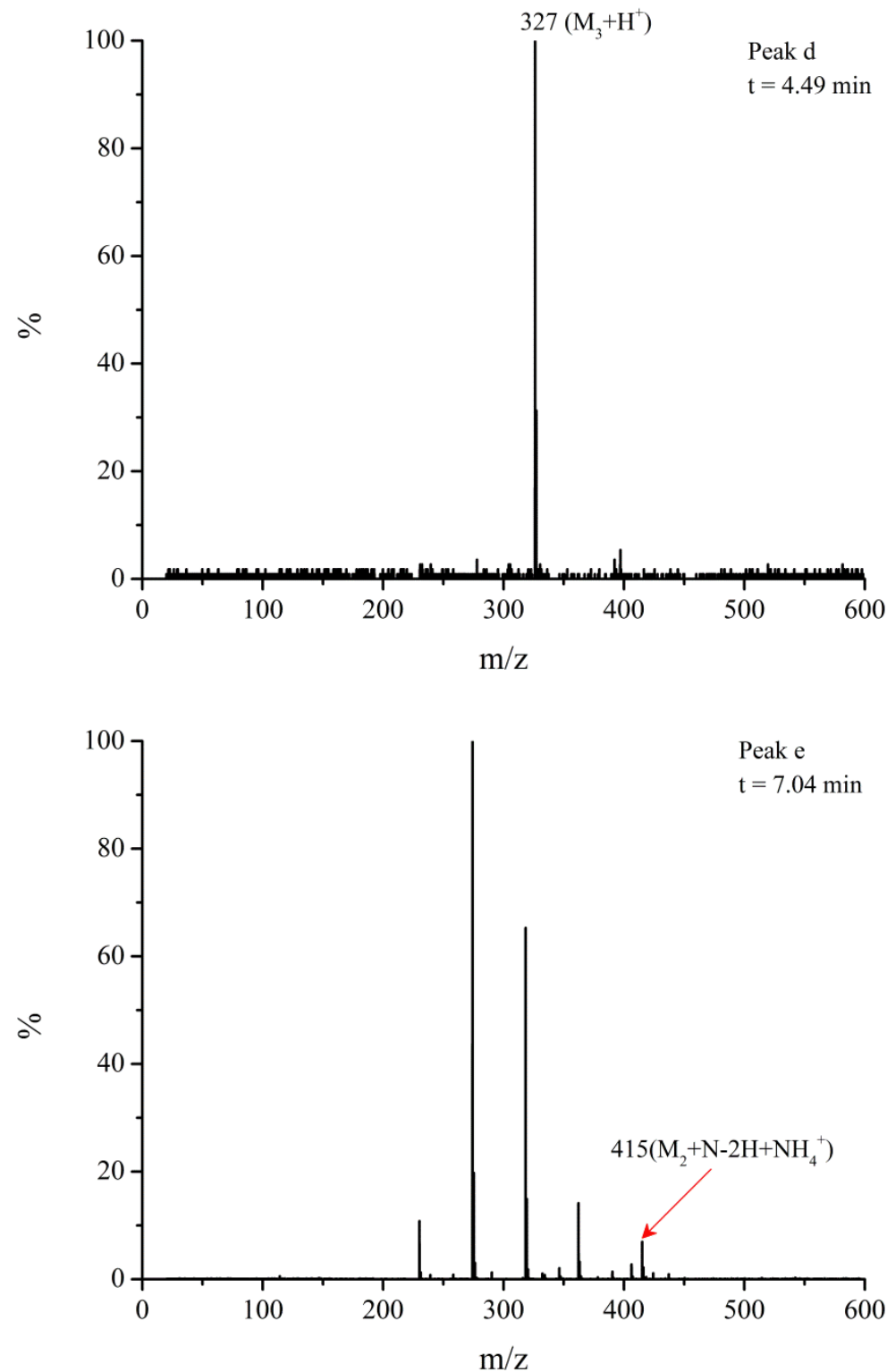

Fig. 6 ESI-MS full-scan spectra under each UPLC peak

(M: HQ; $\mathrm{M}_{2}$ : HQ dimer; $\mathrm{M}_{3}$ : HQ trimer; N: GAH) 


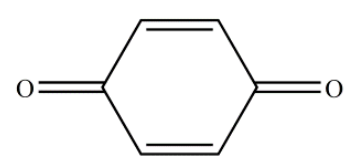

HQ m/z 108

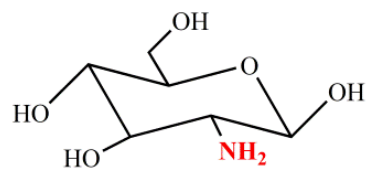

GAH m/z 179

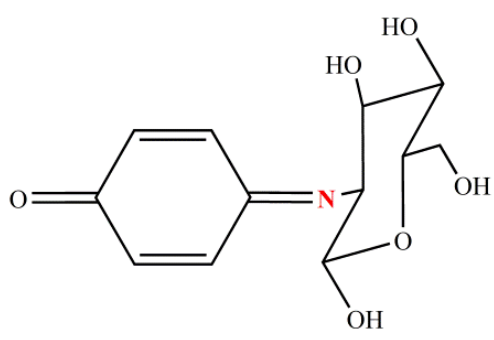

HQ/GAH complex m/z 269<smiles></smiles>

HQ dimer/GAH m/z 397<smiles>O=C1C=CC(=O)C(C2=CC(=O)C=C(C3=CC(=O)C=CC3=O)C2=O)=C1</smiles>

HQ trimer $\mathrm{m} / \mathrm{z} 320$<smiles>O=C1CC=C(O)C=C1Oc1ccc(O)cc1Oc1ccc(O)cc1</smiles>

HQ trimer $\mathrm{m} / \mathrm{z} 326$<smiles></smiles>

HQ dimer/GAH m/z 397

Fig.7 Possible structures of HQ derivatives under the catalysis of laccase and PHQ/GAH complex

\section{Properties of Polymerized Hydroquinone and Functionalized Cotton Fabrics}

Thermal Properties of PHQ and PHQ/COS Complex 

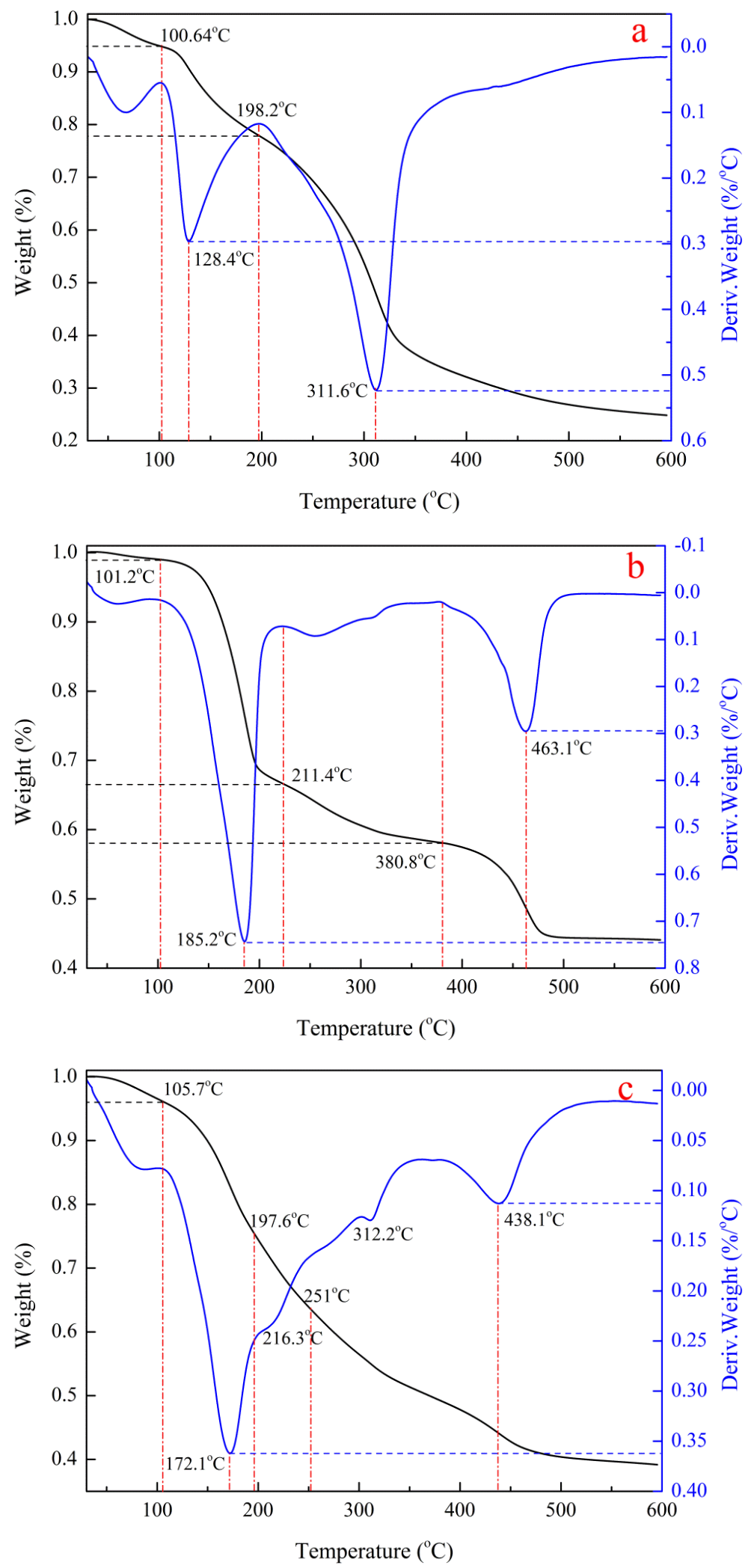

Fig. 8 TG and DTG plots for COS (a), PHQ (b) and PHQ/COS complex (c)

TGA and DTG have been widely used to evaluate thermal properties of materials and to show the mechanism by which the mass of materials changes over time as the temperature 
changes because of thermal decomposition of materials. The thermogravimetric analysis of PHQ, PHQ/COS complex and COS has been performed, and the results of TGA and DTG (the first derivative of weight loss) curves were shown in Fig. 8. For the curves of laccase-synthesized polymer PHQ, only $1 \%$ of weight loss occurred at the initial stage. The weight of PHQ decreased with increasing temperature, including two evident stages of weight loss: $32.26 \%$ at the temperature range of $101.2-221.4^{\circ} \mathrm{C}$ with a major DTG peak $\left(0.743 \mathrm{wt} . \% /{ }^{\circ} \mathrm{C}\right)$ at $185.2^{\circ} \mathrm{C}$ and $13.98 \%$ at the temperature range of $380.8-600^{\circ} \mathrm{C}$ with a minor DTG peak $\left(0.295 \mathrm{wt} . \% /{ }^{\circ} \mathrm{C}\right)$ at $463.1^{\circ} \mathrm{C}$.

After PHQ was grafted onto COS (Fig. 8c), the first weight loss could be found from 30 to $105.7^{\circ} \mathrm{C}$, possibly due to the loss of free water in the PHQ/COS complex sample, which was in accordance with the first stage of weight loss of COS in Fig. 8a. According to the literature, the temperature of dehydration of the saccharide rings and degradation of COS occurs between 100 and $400{ }^{\circ} \mathrm{C}$ [31]. Below $197.6^{\circ} \mathrm{C}$ (the second stage $105.7^{\circ} \mathrm{C}-197.6^{\circ} \mathrm{C}$ ), it may correspond to the loss of bound water and acetic acid from the solvent; from 251 to $375^{\circ} \mathrm{C}$ (fourth stage), the mass loss is mainly due to degradation of $\operatorname{COS}[39,40]$. Above $375^{\circ} \mathrm{C}$ (fifth stage), it could be caused by depolymerization of the PHQ. Therefore, the third stage of weight loss starts at $197.6^{\circ} \mathrm{C}$ and continues up to $251^{\circ} \mathrm{C}$ during which there was $13.4 \%$ mass loss due to the cleavage of the bond between COS and PHQ. Obviously, the result of TGA and DTG also demonstrated that the stable chemical bonds exist between PHQ and COS. 


\section{Dyeing Depth of Treated Cotton Fabrics}

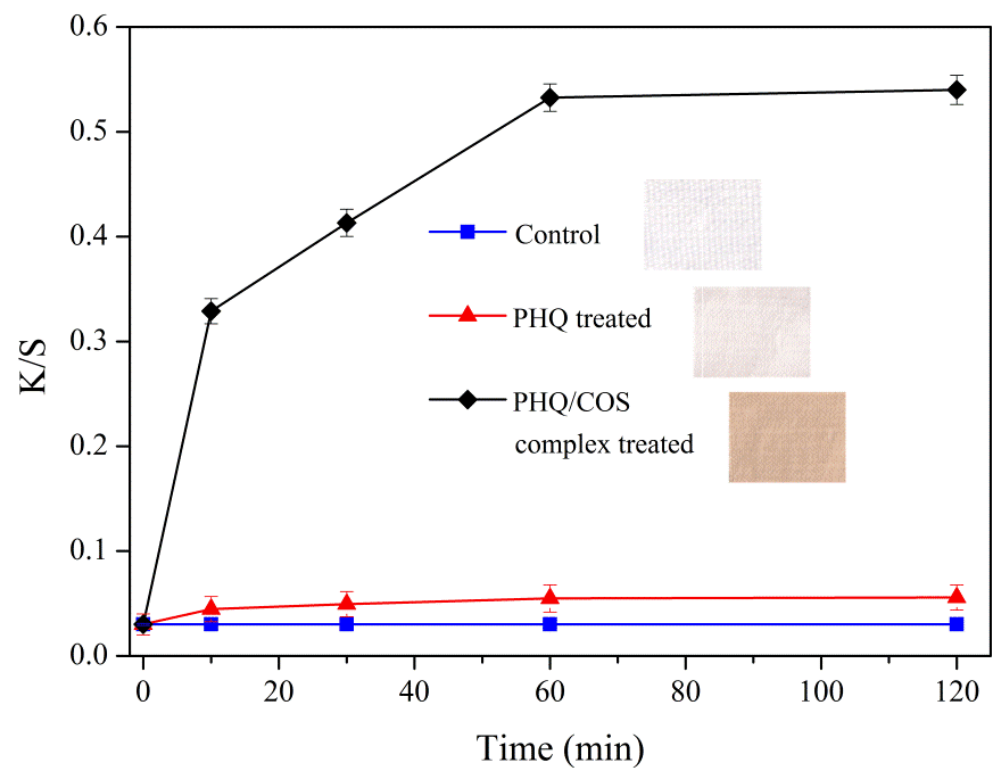

Fig. $9 \mathrm{~K} / \mathrm{S}$ values of the cotton fabrics treated with PHQ and PHQ/COS (the inserted pictures were control,

PHQ treated, and PHQ/COS complex treated fabrics, respectively).

Laccase-catalyzed polymerization of HQ in the presence of COS was undertaken to form the PHQ/COS complex which showed the brown color due to the conjugated structure (chromophore) of PHQ. This colored compound could be used as polymeric colorants for the dyeing of textile fabrics. Cotton fabrics were treated with PHQ or PHQ/COS complex through in-situ laccase catalysis and the K/S values of dyed cotton fabrics were shown in Fig. 9. The K/S values of PHQ/COS complex treated cotton fabrics increased with the treatment time. After 5 hour treatment, PHQ treated cotton fabric was almost colorless, while PHQ/COS complex treated cotton fabric achieved a light brown color. Photographs of the control and treated cotton fabrics were presented in Fig. 9 (Inserted images). In previous enzymatic dyeing techniques, cotton fabrics are difficult to be colored with polymeric colorants through in-situ laccase-catalyzed oxidation and polymerization, because cellulose fibers do not have amino groups as wool fibers to be involved in the reaction with colored polymers during laccase-catalyzed polymerization[41]. 
For instance, Hadzhiyska et al. selected two monomers (2,5-diaminobenzenesulfonic acid and catechol) to dye the bleached cotton fabrics by laccase-catalyzed polymerization to get better coloration[42]; Kim et al. utilized the natural flavonoids present in cotton as anchors to attach other phenolic compounds to the fiber surface[43]. The concept presented in this paper is the utilization of COS as a template, not only providing a fibre surface layer for HQ monomers to be polymerized but also forming covalent bonds between polymerized HQ and amino groups of COS, resulting in the fixation of the colored polymer on cotton fabrics. This study provides a novel and facile coloration method for cotton fabrics that are difficult to be dyed with polyphenols.

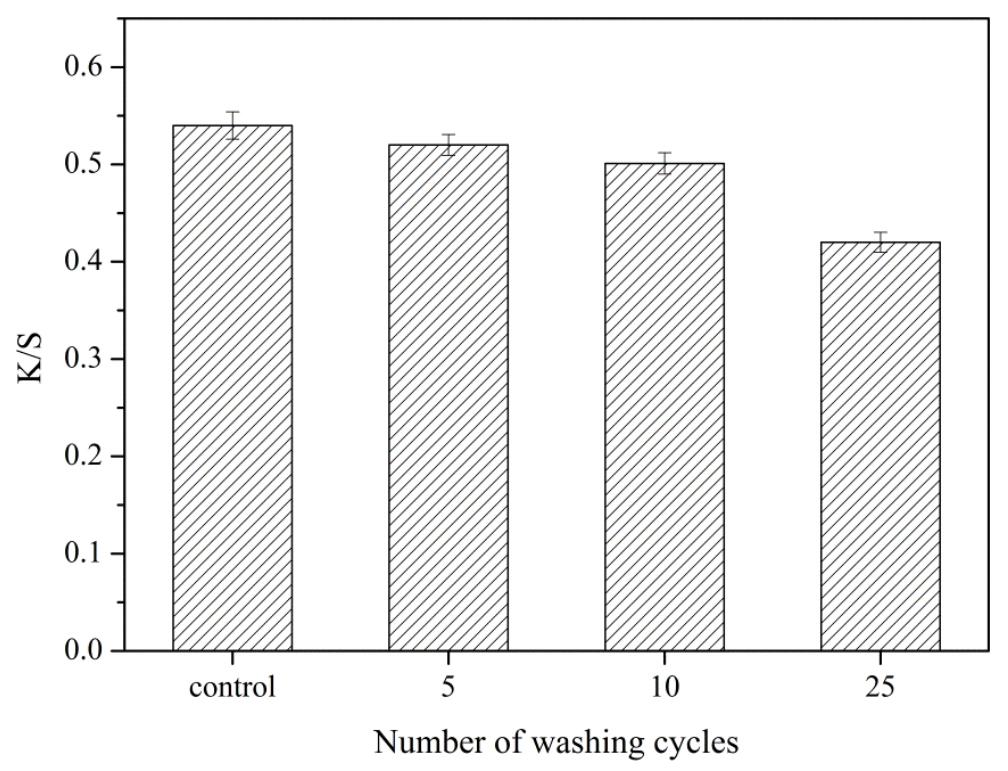

Fig. $10 \mathrm{~K} / \mathrm{S}$ values of treated cotton samples after different washing strength

The color durability result of cotton fabrics treated with PHQ/COS complex was presented in Fig.10. The K/S value of dyed cotton fabric almost unchanged during the first 10 times of washing; after 25 cycles of water washing, there is minor decrement in the K/S value of dyed cotton fabric. These data suggested that PHQ/COS complex treated cotton fabric had good durability to color. 


\section{Antibacterial Activities of Cotton Fabrics}

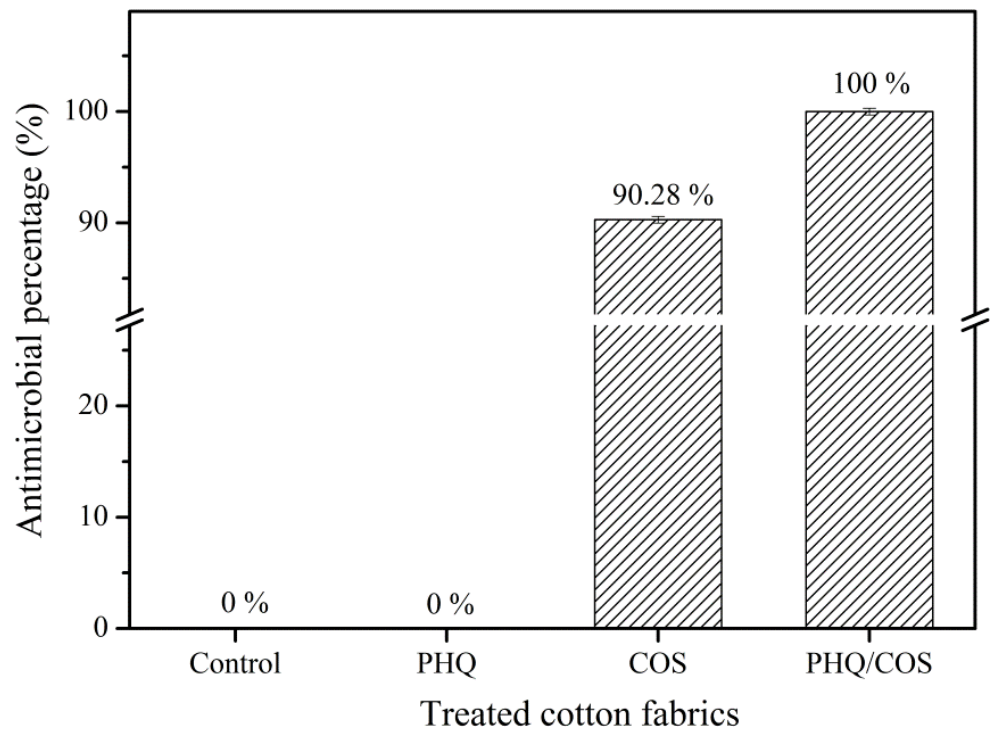

Fig. 11 Antibacterial activity of the functionalized cotton fabrics

Because chitosan oligosaccharide (COS) has good antibacterial properties, the cotton dyed with $\mathrm{PHQ} / \mathrm{COS}$ was tested to assess its antibacterial activity against $E$. coli. Fig. 11 shows the result of antibacterial activities of different cotton fabrics against $E$. coli. It can be seen that both control cotton fabrics and PHQ treated cotton fabrics did not exhibit any antibacterial effects. It may be because there was almost no poly(hydroquinone) being able to absorb on the surface of cotton fibers as shown in Fig. 9. For the cotton fabrics treated with COS and PHQ/COS complex, the antimicrobial percentage against bacteria reached $90.28 \%$ and $100 \%$, respectively, according to the Equation (2) $[44,45]$. The PHQ/COS complex treated cotton fabrics possessed strong antibacterial activity against $E$. coli, because no noticeable colonies were detected. This could be due to antibacterial properties from both COS and polymerized phenols which were successfully coated on the surface of cotton fabrics in the form of PHQ/COS complex. 


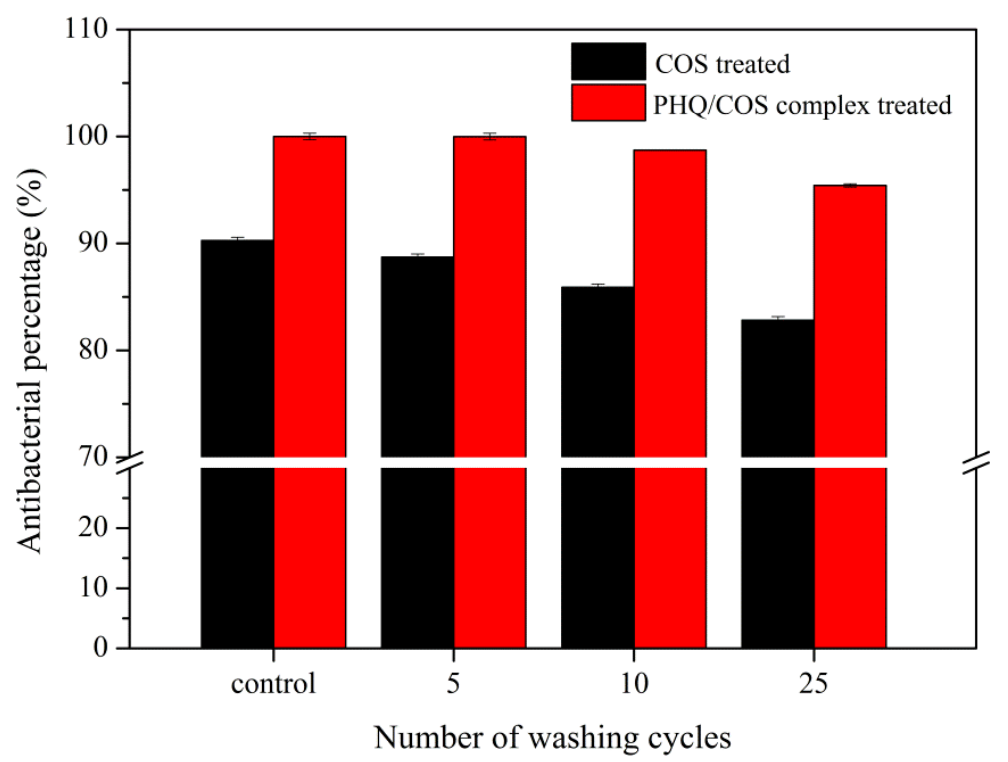

Fig. 12 Antibacterial activity of cotton samples treated with COS and PHQ/COS complex after different washing strength

Fig. 12 presented the result of antibacterial durability of cotton samples treated with COS and PHQ/COS complex. Comparison of all data demonstrated that antibacterial percentage of both types of the treated cotton fabrics remained almost the same during the first 5 washing cycles. After 10 and 25 washing cycles, the antibacterial percentage of cotton fabric treated with COS complex decreased more than that treated with PHQ/COS complex, which showed good antibacterial durability of the PHQ/COS complex treated cotton fabrics after repeated water washing.

\section{Conclusions}

In this work, polyhydroquinone/chitosan oligosaccharide (PHQ/COS) complex was synthesized through laccase catalysis. Glucosamine hydrochloride was used as the model compound of COS in the investigation through UPLC-TOD-ESI-MS analysis to understand the possible structures of $\mathrm{PHQ} / \mathrm{COS}$ complex. During the polymerization of hydroquinone, COS is used as a surface coating on cotton fibres for reaction with PHQ through covalent bonding 
according to the mechanism of Schiff base or Michael addition reactions. In addition, the synthesized PHQ/COS complex can be applied for dyeing and functionalization of cotton fabrics to achieve colored cotton fabrics with good antibacterial activity. It solves the problem that cotton fabric cannot be colored by some polyphenols using enzymatic polymerization. The current study develops a new path for biosynthesis of polyphenols on the basis of COS, which can produce antimicrobial function. Moreover, this COS-incorporated polymerization of phenols through laccase catalysis also permits novel and facile coloration and functionalization of cotton. This approach shows great potential for the modification of other cellulosic materials.

\section{Acknowledgments}

This work was financially supported by the National Natural Science Foundation of China (51673087, 31771039), China Scholarship Council (CSC_201706790038), the Program for Changjiang Scholars and Innovative Research Teams in Universities (IRT_15R26), Fundamental Research Funds for the Central Universities (JUSRP51717A) and the Graduate student innovation project (KYLX16_0800).

The authors have declared no conflict of interest.

\section{References}

1. Sun, T., Zhu, Y., Xie, J., \& Yin, X. (2011). Antioxidant activity of N-acyl chitosan oligosaccharide with same substituting degree. Bioorganic \& Medicinal Chemistry Letters, 21(2), 798-800.

2. Dodane, V., \& Vilivalam, V. D. (1998). Pharmaceutical applications of chitosan. Pharmaceutical Science \& Technology Today, 1(6), 246-253. 
3. Zhao, D., Wang, J., Tan, L., Sun, C., \& Dong, J. (2013). Synthesis of N-furoyl chitosan and chito-oligosaccharides and evaluation of their antioxidant activity in vitro. International Journal of Biological Macromolecules, 59, 391-395.

4. Zhou, Y., Yang, H., Liu, X., Mao, J., Gu, S., \& Xu, W. (2013). Electrospinning of carboxyethyl chitosan/poly(vinyl alcohol)/silk fibroin nanoparticles for wound dressings. International Journal of Biological Macromolecules, 53(2), 88-92.

5. Sekiguchi, S., Miura, Y., Kaneko, H., Nishimura, S. I., Nishi, N., Iwase, M., \& Tokura, S. (1994). Molecular Weight Dependency of Antimicrobial Activity by Chitosan Oligomers. In Nishinari K., \& Doi E. (Eds.), Food Hydrocolloids (pp. 71-76). Springer, Boston, MA.

6. Du, Y. Z., Wang, L., Yuan, H., Wei, X. H., \& Hu, F. Q. (2009). Preparation and characteristics of linoleic acid-grafted chitosan oligosaccharide micelles as a carrier for doxorubicin. Colloids and Surfaces B: Biointerfaces, 69(2), 257-263.

7. Lin, S. B., Chen, S. H., \& Peng, K. C. (2009). Preparation of antibacterial chito-oligosaccharide by altering the degree of deacetylation of $\beta$-chitosan in a Trichoderma harzianum chitinasehydrolysing process. Journal of the Science of Food and Agriculture, 89(2), 238-244.

8. Crini, G. (2005). Recent developments in polysaccharide-based materials used as adsorbents in wastewater treatment. Progress in Polymer Science, 30(1), 38-70.

9. Berger, J., Reist, M., Mayer, J. M., Felt, O., Peppas, N. A., \& Gurny, R. (2004). Structure and interactions in covalently and ionically crosslinked chitosan hydrogels for biomedical applications. European Journal of Pharmaceutics and Biopharmaceutics, 57(1), 19-34.

10. Je, J. Y., Park, P. J., \& Kim, S. K. (2004). Free radical scavenging properties of heterochitooligosaccharides using an ESR spectroscopy. Food and Chemical Toxicology, 42(3), 
381-387.

11. Eom, T. K., Senevirathne, M., \& Kim, S. K. (2012). Synthesis of phenolic acid conjugated chitooligosaccharides and evaluation of their antioxidant activity. Environmental Toxicology and Pharmacology, 34(2), 519-527.

12. Tikhonov, V. E., Stepnova, E. A., Babak, V. G., Yamskov, I. A., Palma-Guerrero, J., Jansson, H. B., Lopez-Llorca, L.V., Salinas, J., Gerasimenko, D.V., Avdienko, I.D. \& Varlamov, V. P. (2006). Bactericidal and antifungal activities of a low molecular weight chitosan and its N-/2 (3)-(dodec-2-enyl) succinoyl/-derivatives. Carbohydrate Polymers, 64(1), 66-72.

13. Toshkova, R., Manolova, N., Gardeva, E., Ignatova, M., Yossifova, L., Rashkov, I., \& Alexandrov, M. (2010). Antitumor activity of quaternized chitosan-based electrospun implants against Graffi myeloid tumor. International Journal of Pharmaceutics, 400(1-2), 221-233.

14. Kim, S. K., \& Rajapakse, N. (2005). Enzymatic production and biological activities of chitosan oligosaccharides (COS): A review. Carbohydrate Polymers, 62(4), 357-368.

15. Han, J., \& Li, X. (2011). Chemoenzymatic syntheses of sialyl Lewis X-chitosan conjugate as potential anti-inflammatory agent. Carbohydrate Polymers, 83(1), 137-143.

16. Junker, K., Zandomeneghi, G., Schuler, L. D., Kissner, R., \& Walde, P. (2015). Enzymatic polymerization of pyrrole with Trametes versicolor laccase and dioxygen in the presence of vesicles formed from AOT (sodium bis-(2-ethylhexyl) sulfosuccinate) as templates. Synthetic Metals, 200, 123-134.

17. Kobayashi, S. (1999). Enzymatic polymerization: a new method of polymer synthesis. Journal of Polymer Science Part A: Polymer Chemistry, 37(16), 3041-3056. 
18. Kobayashi, S., Uyama, H., \& Kimura, S. (2001). Enzymatic polymerization. Chemical Reviews, 101(12), 3793-3818.

19. Desentis-Mendoza, R. M., Hernández-Sánchez, H., Moreno, A., Rojas del C, E., ChelGuerrero, L., Tamariz, J., \& Jaramillo-Flores, M. E. (2006). Enzymatic polymerization of phenolic compounds using laccase and tyrosinase from ustilago $\mathrm{m}$ aydis. Biomacromolecules, 7(6), 1845-1854.

20. Zhang, L., Zhao, W., Ma, Z., Nie, G., \& Cui, Y. (2012). Enzymatic polymerization of phenol catalyzed by horseradish peroxidase in aqueous micelle system. European Polymer Journal, $48(3), 580-585$.

21. Kim, Y. J., Uyama, H., \& Kobayashi, S. (2003). Regioselective synthesis of poly (phenylene) as a complex with poly (ethylene glycol) by template polymerization of phenol in water. Macromolecules, 36(14), 5058-5060.

22. Kim, Y. J., Uyama, H., \& Kobayashi, S. (2004). Peroxidase-catalyzed oxidative polymerization of phenol with a nonionic polymer surfactant template in water. Macromolecular Bioscience, 4(5), 497-502.

23. Kim, Y. J., Shibata, K., Uyama, H., \& Kobayashi, S. (2008). Synthesis of ultrahigh molecular weight phenolic polymers by enzymatic polymerization in the presence of amphiphilic triblock copolymer in water. Polymer, 49(22), 4791-4795.

24. Bai, R., Yu, Y., Wang, Q., Fan, X., Wang, P., Yuan, J., \& Shen, J. (2018). Laccase-catalyzed poly (ethylene glycol)-templated 'zip'polymerization of caffeic acid for functionalization of wool fabrics. Journal of Cleaner Production, 191, 48-56.

25. Shou, D., Dong, Y., Shen, L., Wu, R., Zhang, Y., Zhang, C., \& Zhu, Y. (2013). Rapid 
quantification of tobramycin and vancomycin by UPLC-TQD and application to osteomyelitis patient samples. Journal of Chromatographic Science, 52(6), 501-507.

26. Zhou, Q., Cui, L., Ren, L., Wang, P., Deng, C., Wang, Q., \& Fan, X. (2018). Preparation of a multifunctional fibroin-based biomaterial via laccase-assisted grafting of chitooligosaccharide. International Journal of Biological Macromolecules, 113, 1062-1072.

27. Liu, Y., Li, J., Cheng, X., Ren, X., \& Huang, T. (2015). Self-assembled antibacterial coating by N-halamine polyelectrolytes on a cellulose substrate. Journal of Materials Chemistry B, 3(7), 1446-1454.

28. Sakai, S., Yamada, Y., Zenke, T., \& Kawakami, K. (2009). Novel chitosan derivative soluble at neutral $\mathrm{pH}$ and in-situ gellable via peroxidase-catalyzed enzymatic reaction. Journal of Materials Chemistry, 19(2), 230-235.

29. Calafell, M., Díaz, C., Hadzhiyska, H., Gibert, J. M., Dagà, J. M., \& Tzanov, T. (2007). Biocatalyzed coloration of cellulose fibers. Biocatalysis and Biotransformation, 25(2-4), 336340.

30. Sun, X., Bai, R., Zhang, Y., Wang, Q., Fan, X., Yuan, J., \& Wang, P. (2013). Laccase-catalyzed oxidative polymerization of phenolic compounds. Applied Biochemistry and Biotechnology, 171(7), 1673-1680.

31. Liu, H., Liu, X., Yue, L., Jiang, Q., \& Xia, W. (2016). Synthesis, characterization and bioactivities of $\mathrm{N}$, O-carbonylated chitosan. International Journal of Biological Macromolecules, 91, 220-226.

32. Appunni, S., Rajesh, M. P., \& Prabhakar, S. (2016). Nitrate decontamination through functionalized chitosan in brackish water. Carbohydrate Polymers, 147, 525-532. 
33. Kamari, A., Aljafree, N. F. A., \& Yusoff, S. N. M. (2016). N, N-dimethylhexadecyl carboxymethyl chitosan as a potential carrier agent for rotenone. International Journal of Biological Macromolecules, 88, 263-272.

34. Muzzarelli, R. A., Tanfani, F., Scarpini, G., \& Laterza, G. (1980). The degree of acetylation of chitins by gas chromatography and infrared spectroscopy. Journal of Biochemical and Biophysical Methods, 2(5), 299-306.

35. Sousa, F., Guebitz, G. M., \& Kokol, V. (2009). Antimicrobial and antioxidant properties of chitosan enzymatically functionalized with flavonoids. Process Biochemistry, 44(7), 749756.

36. Božič, M., Gorgieva, S., \& Kokol, V. (2012). Homogeneous and heterogeneous methods for laccase-mediated functionalization of chitosan by tannic acid and quercetin. Carbohydrate Polymers, 89(3), 854-864.

37. Liu, X., Xu, Y., Yu, J., Li, S., Wang, J., Wang, C., \& Chu, F. (2014). Integration of lignin and acrylic monomers towards grafted copolymers by free radical polymerization. International Journal of Biological Macromolecules, 67, 483-489.

38. Mita, N., Tawaki, S. I., Uyama, H., \& Kobayashi, S. (2002). Enzymatic oxidative polymerization of phenol in an aqueous solution in the presence of a catalytic amount of cyclodextrin. Macromolecular Bioscience, 2(3), 127-130.

39. Li, X., Liu, B. O., Wang, X., Han, Y., Su, H., Zeng, X., \& Sun, R. C. (2012). Synthesis, characterization and antioxidant activity of quaternized carboxymethyl chitosan oligosaccharides. Journal of Macromolecular Science, Part A, 49(10), 861-868.

40. Rao, V., \& Johns, J. (2008). Thermal behavior of chitosan/natural rubber latex blends tg and 
dsc analysis. Journal of Thermal Analysis and Calorimetry, 92(3), 801-806.

41. Kim, S. Y., Zille, A., Murkovic, M., Guebitz, G., \& Cavaco-Paulo, A. (2007). Enzymatic polymerization on the surface of functionalized cellulose fibers. Enzyme and Microbial Technology, 40(7), 1782-1787.

42. Hadzhiyska, H., Calafell, M., Gibert, J. M., Daga, J. M., \& Tzanov, T. (2006). Laccaseassisted dyeing of cotton. Biotechnology Letters, 28(10), 755-759.

43. Kim, S., Moldes, D., \& Cavaco-Paulo, A. (2007) Laccases for enzymatic coloration of unbleached cotton. Enzyme and Microbial Technology, 40(7): 1788-1793.

44. Yue, L., Li, J., Chen, W., Liu, X., Jiang, Q., \& Xia, W. (2017). Geraniol grafted chitosan oligosaccharide as a potential antibacterial agent. Carbohydrate Polymers, 176, 356-364.

45. Aytac, Z., Yildiz, Z. I., Kayaci-Senirmak, F., San Keskin, N. O., Tekinay, T., \& Uyar, T. (2016). Electrospinning of polymer-free cyclodextrin/geraniol-inclusion complex nanofibers: Enhanced shelf-life of geraniol with antibacterial and antioxidant properties. RSC Advances, 6(52), 46089-46099. 